\title{
Rituximab regulates signaling pathways and alters gene expression associated with cell death and survival in diffuse large B-cell lymphoma
}

\author{
SATU KOIVULA ${ }^{1,2}$, ERKKA VALO ${ }^{2,3}$, ANNA RAUNIO ${ }^{2,4}$, SAMPSA HAUTANIEMI ${ }^{2,3}$ and SIRPA LEPPÄ ${ }^{1,2}$ \\ ${ }^{1}$ Department of Oncology, Helsinki University Central Hospital, Helsinki; ${ }^{2}$ Genome-Scale Biology Research \\ Program, University of Helsinki, Helsinki; ${ }^{3}$ Institute of Biomedicine, University of Helsinki, Helsinki; \\ ${ }^{4}$ Department of Pathology, Haartman Institute, University of Helsinki, Helsinki, Finland
}

Received November 16, 2010; Accepted December 29, 2010

DOI: $10.3892 /$ or.2011.1179

\begin{abstract}
Rituximab, a CD20-specific antibody, is used with chemotherapy as a treatment for diffuse large B cell lymphoma (DLBCL). Although many patients benefit from the addition of rituximab to chemotherapy, a favourable response is not achieved in approximately $30 \%$ of cases. This sets a prerequisite to better understand the response and resistance mechanisms of rituximab. To do so, we analyzed the gene expression profiles of one rituximab unresponsive and two responsive DLBCL cell lines. In the responsive cells, rituximab affected the expression of genes related to apoptosis, lymphocyte signaling and cytokine response. Our data show rituximab-response to be associated with gene expression in classical signaling cascades involved in cell growth and differentiation, such as previously identified MAPK and completely novel Wnt and TGF- $\beta$ pathways. Furthermore, our findings support earlier observations that rituximab can induce direct apoptosis and suggest the cell of origin to be associated with the cellular outcome. After validation of cellular results, we used a cohort of 233 R-CHOP treated DLBCL patients and found several of the most differentiating genes to have impact on survival. Together, the results provide an advanced picture of the CD20 mediated signaling of DLBCL cells and may provide new targets in future treatment protocols.
\end{abstract}

\section{Introduction}

Rituximab is a chimeric monoclonal antibody that targets the CD20 molecule on the surfaces of normal and malignant pre-B and mature $\mathrm{B}$ lymphocytes. It has been suggested that $\mathrm{CD} 20$ is involved in the regulation of intracellular $\mathrm{Ca}^{++}$levels

Correspondence to: Dr Sirpa Leppä, Department of Oncology, Helsinki University Central Hospital, P.O. Box 180, FIN-00029 Helsinki, Finland

E-mail: sirpa.leppa@helsinki.fi

Key words: rituximab, diffuse large B-cell lymphoma, gene expression, apoptosis and may play a role in B-cell proliferation and differentiation $(1,2)$. CD20 activity has also been described to be associated with B-cell receptor activation through the induction of Src family tyrosine kinases and the activation of the MAPK pathway (3-5). Conversely, rituximab has been shown to inhibit B-cell receptor signaling, and pathways involving MAPK, PI3K/Akt, NF-kB and mTOR (6-8).

Rituximab has provided a great improvement to the treatment of B-cell non-Hodgkin lymphomas. The benefit of rituximab has been especially seen in diffuse large B-cell lymphoma (DLBCL), where the addition of rituximab to chemotherapy has improved the overall survival of the patients to $50-80 \%$ (9-11). Despite this remarkable success, not all patients respond to therapy and it would be of great importance to fully understand the response and resistance mechanisms to rituximab, and thereby prepare the means for predicting the patients' outcome.

DLBCL is a heterogenic disease, which makes targeting of the therapy difficult. According to gene expression profiling, DLBCL can be divided at least into two molecular entities, a germinal center B-cell (GC) and an activated B-cell (ABC) like subtypes. The subgroups were initially separated with gene signatures that differentiated cells by their stage of B-cell differentiation and activation $(12,13)$. The DLBCL subtype as identified by gene signature also correlated with prognosis, as the patients with germinal cell like DLBCL had better outcome than the ones with activated B-cell like disease (12-14).

To date, there is still no absolute consensus of the in vivo mechanism of actions of rituximab. Based on in vitro studies, rituximab appears to mediate the depletion of B-cells by several mechanisms that are dependent on the host immune system, including complement-dependent and antibodydependent cellular cytotoxicities (15-17). The direct activities of rituximab are less well understood. It has been proposed that rituximab may sensitize lymphoma cells to chemotherapy, and may have direct antiproliferative and apoptotic effects $(4,5,18,19)$. However, most of the data on rituximab has been produced on Burkitt lymphoma and chronic lymphocytic leukemia cells. Furthermore, for various reasons, not all CD20 positive lymphomas respond favourably to rituximab. 
Against this background, we set out experiments to identify endogenous response mechanisms of DLBCL cells to rituximab treatment. We examined the effect of rituximab on the global gene expression in rituximab responsive and unresponsive DLBCL cell lines, and associated the findings with cellular outcome and survival of the patients.

\section{Materials and methods}

Cell culture. Three established human DLBCL cell lines OCILy-3, OCI-Ly-10 and SuDHL-4 were a kind gift from Dr Jose A. Martinez-Climent (Centro de Investigacion Medica Aplicada). The cells were cultured in a humidified $5 \% \mathrm{CO}_{2}$ atmosphere at $37^{\circ} \mathrm{C}$. OCI-LY-3 and OCI-Ly-10 cells were cultured in Iscove's modified essential medium (IMDM) supplemented with $20 \%$ human serum, $2 \mathrm{mM}$ glutamine, $100 \mathrm{units} / \mathrm{ml}$ penicillin, $100 \mu \mathrm{g} / \mathrm{ml}$ streptomycin and $55 \mu \mathrm{M}$ $\beta$-mercaptoethanol and SuDHL-4 cells in RPMI-1640 supplemented with $10 \%$ fetal bovine serum, $2 \mathrm{mM}$ glutamine, $100 \mathrm{unit} / \mathrm{ml}$ penicillin and $100 \mu \mathrm{g} / \mathrm{ml}$ streptomycin.

Proliferation assays, SDS-PAGE, cell cycle and apoptosis analysis. For the viability assays the cells were plated on 96-microwell plates in the density of $3 \times 10^{5}$ OCILy- 3 and OCILy-10 cells $/ \mathrm{ml}$ or $2.5 \times 10^{5} \mathrm{SuDHL}-4$ cells $/ \mathrm{ml}$ and grown with or without rituximab (10 $\mu \mathrm{g} / \mathrm{ml}$, MabThera ${ }^{\circledR}$, Roche, Switzerland) for 24-72 $\mathrm{h}$ before measuring the cell viability with XTT proliferation reagent (Roche Diagnostics $\mathrm{GmbH}$, Switzerland) according to manufacturer's instructions.

The SDS-PAGE was performed as previously described (20). The antibodies against Bcl-6 and MUM1/IRF4 were from Dako Cytomation (Glostrup, Denmark), against CD10 from Novocastra Laboratories Ltd. (Newcastle upon Tyne, UK) and against actin from Santa Cruz Biotechnology Inc. (Santa Cruz, CA, USA). For the detection of cell cycle distribution and cell death, the cells were grown with or without rituximab for $48 \mathrm{~h}$ and stained with propidium iodide $[(50 \mathrm{mg} / \mathrm{ml}$ (TX-100 0.1\%; Na-sitrate 0,5\%)] overnight or with Annexin $\mathrm{V}$ and propidium iodide using a FITC Annexin V Apoptosis Detection Kit I (Becton-Dickinson Biosciences, San Jose, CA, USA) according to the manufacturer's instructions. The cells were sorted with FACS Cell Calibur (BectonDickinson, Bedford, MA, USA) equipment and analysed with CellQuestPro (Becton-Dickinson) and ModFit (Verity Software House Inc., Topsham, ME, USA) software.

RNA isolation, gene expression profiling and data analyses. Cells were stimulated with $10 \mu \mathrm{g} / \mathrm{ml}$ rituximab for $3 \mathrm{~h}$ before extracting RNA with Nucleospin RNA II kit (Macherey-Nagel GmbH \& Co., Düren, Germany) according to manufacturer's instructions. mRNA from rituximab treated cells was labelled with Cy3-dUTP and mRNA from untreated control cells was labelled with Cy5-dUTP and hybridized onto Agilent Human 44K oligonucleotide microarrays (Agilent Technologies, Palo Alto, CA, USA). Signal values were calculated with Agilent Scanner.

All cell line microarray analyses were done with Ensembl human genome version 57 (21). The GO enrichment analysis was conducted using Fisher's exact test. All P-values in the analyses were adjusted using false discovery rate (FDR) multiple hypothesis correction method (22). A probe was removed from the analysis if signal for both channels was saturated or signal values for channels belonged to the lowest 5\% in the respective channel. Probes with identical sequence were combined using median of the normalized values. Probes that mapped to multiple Ensembl Gene IDs or EntrezGene IDs were filtered out of the analysis as uninformative. Microarray data are available at ArrayExpress archive (ID: E-MEXP-2317).

Based on the findings showing that OCILy-3 cells did not decrease their growth in response to rituximab they were described as 'non-responsive'. On the contrary, identical rituximab treatment significantly changed cell growth of the cell lines SuDHL-4 and OCILy-10 and thus these two cell lines were named 'responsive'.

Real-time PCR. Total RNA (1 $\mu \mathrm{g})$ was reverse transcribed in a final volume of $20 \mu \mathrm{l}$ with High Capasity cDNA Reverse Trancription kit reagents (Applied Biosysytems, Carlsbad, CA, USA) for $10 \mathrm{~min}$ at $25^{\circ} \mathrm{C}$ followed by $120 \mathrm{~min}$ at $120^{\circ} \mathrm{C}$ and finally for $5 \mathrm{sec}$ in $85^{\circ} \mathrm{C}$. A total of $2 \mu 1$ of reverse trancriptase product was amplified in triplicate in a $30 \mu \mathrm{l}$ reaction using the Taqman Fast Universal Mix (Applied Biosystems) and Dkk-1, Pdcd-1 and Ntn-1 Taqman probes (Applied Biosystems). In the amplification reactions we used the Applied Biosystems 7300/7500 Real Time PCR System with 7500 Fast SDS software. The results were normalised comparing the tested gene to a Gapdh housekeeping gene. The fold change was

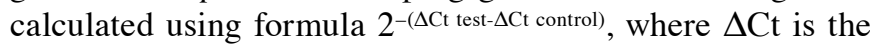
samples mean of cycles for the test gene-mean of cycles for the Gapdh gene.

Patients and survival analyses. In order to analyze the clinical importance of the rituximab responsive vs. non-responsive cell line comparison, a microarray data generated by Lymphoma/ Leukemia Molecular Profiling Project (LLMPP) was used (14). The data set contains mRNA expression data from de novo 233 DLBCL patients treated with combination of rituximab and CHOP-like chemotherapy. Probe sets corresponding to the genes that were most highly up-regulated or suppressed in response to rituximab in cellular analyses were identified from the data set and their expression was associated with patients' outcome. Overall survival (OS) rates were estimated using the Kaplan-Meier method and the differences between the subgroups were compared with the log-rank test. OS was determined from the time of diagnosis to death. P-values were two tailed. We considered $\mathrm{P}<0.05$ as significant. The survival analyses were carried out with PASW 17.0 for Windows (SPSS, Chicago, IL, USA).

\section{Results}

Rituximab responsive cells undergo homotypic aggregation and direct cell death. To determine the direct effects of rituximab on DLBCL cells, we first evaluated the outcome of three DLBCL cell lines in response to rituximab. OCILy-3, OCILy-10 and SuDHL-4 cells were treated with rituximab, and their viability was measured every $24 \mathrm{~h}$ for three days. A couple of hours after rituximab was added to the culture medium, a phenomenon described as homotypic adhesion 


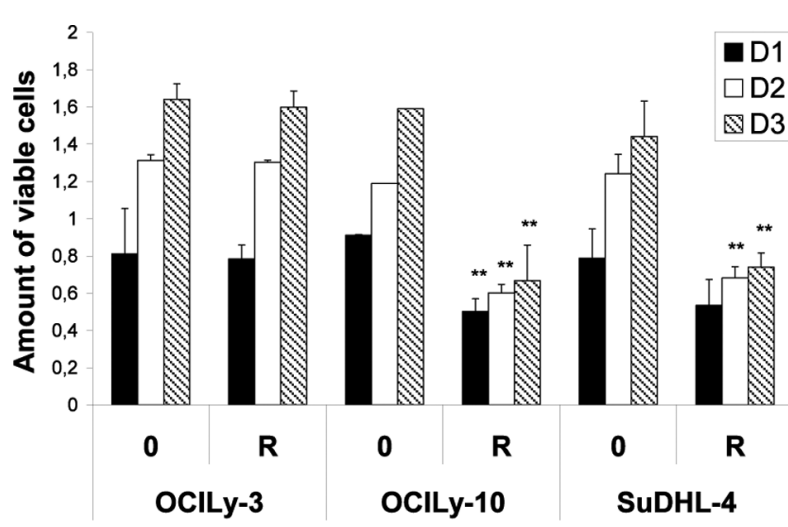

Figure 1. Effect of rituximab on the proliferation of DLBCL cell lines. OCILy-3, OCILy-10 and SuDHL-4 cells were exposed to rituximab, and analyzed for growth at indicated time periods. The values are the mean \pm standard errors of three parallel samples. Statistically significant differences from values for control cells are indicated as follows: ${ }^{* * *} \mathrm{p}<0.01$.

was clearly seen in SuDHL-4 cells and to some extent also in OCILy-10 cells. The aggregates became even denser during the following 24 hours. The observation has been previously described in SuDHL-4 cells (23). The same difference between the cell lines could be seen also in the proliferation assay. Whereas OCILy-10 and SuDHL-4 cells showed a clear reduction in growth, OCILy-3 did not respond to rituximab (Fig. 1). The difference in the suppression of growth between the responsive DLBCLs and OCILy-3 cells was statistically significant $(\mathrm{P}<0.01$ in all cases after $\geq 48 \mathrm{~h})$.

Reduction in cell number is in most cases caused by either cell cycle arrest, cell death or both. In order to find out the reason behind the rituximab-induced growth reduction, the cells were treated with rituximab for two days and monitored by DNA staining with PI and flow cytometry. The cell cycle distributions of both OCILy-3 and SuDHL-4 cells remained virtually unchanged despite rituximab treatment (Fig. 2A). In OCILY-10 cells we observed a small shift from $\mathrm{S}$ to G1 phase that could contribute to reduced cell growth.

As cell cycle arrest could not fully explain the reduction of cells in the growth assays, we next analyzed rituximabinduced direct cell death by staining the cells with Annexin $\mathrm{V}$ and PI. Annexin V binds the membrane phospholipid phosphatidylserine, which is externalized to the plasma membrane in the early stage of apoptosis. Bivariate analysis together with PI enables the recognition of intact cells (FITC PI-), early apoptotic (FITC+PI-) and late apoptotic or necrotic cells $\left(\mathrm{FITC}^{+} \mathrm{PI}^{+}\right)$. The apoptosis assay revealed a moderate increase in the amount of double stained SuDHL-4 cells (17\%) and OCILy-10 cells (18\%), as compared to untreated cells (Fig. 2B). As expected, the rituximab non-responsive OCILy-3 cell line showed no induction of cell death, and the amount of Annexin V and PI positive cells was only $4 \%$ higher in the rituximab treated sample. Another way of analysing direct cell death is to determine the amount of viable i.e. double negative cells (24). This approach is more similar to the growth assay that measures the amount of viable cells. In SuDHL-4 cells the amount of live cells decreased 19\% and the amount of OCILy-10 cells $20 \%$ in response to rituximab,
A

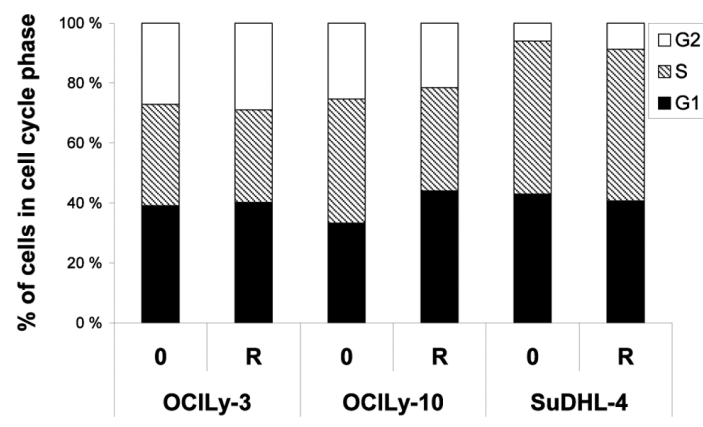

0

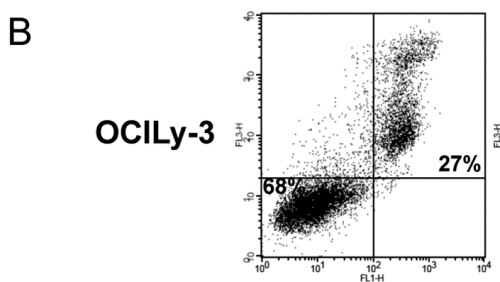

$\mathbf{R}$
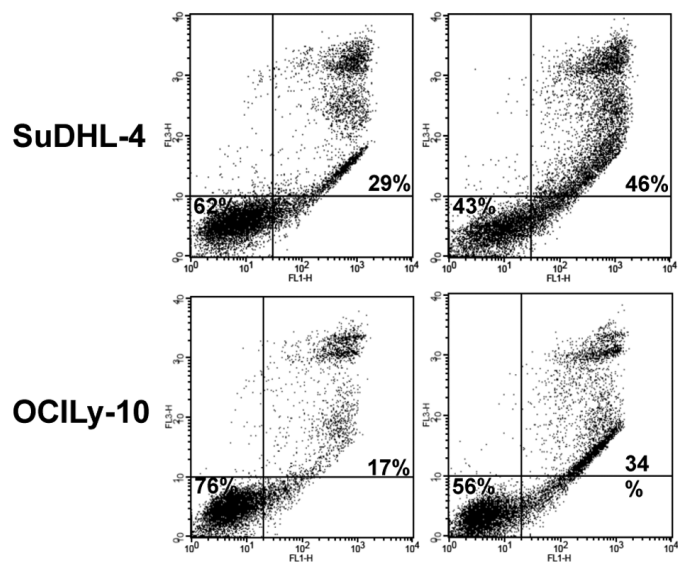

Figure 2. Effect of rituximab on cell cycle distribution and cell death of DLBCL cell lines. (A) Cell cycle distribution after exposure of cells to rituximab. OciLy-3, OciLy-10 and SuDHL-4 cells were left untreated (0) or treated with rituximab (R) and after $48 \mathrm{~h}$ harvested into hypotonic propidium iodine-solution, and analyzed for cell cycle distribution by FACS. (B) Cell death in response to rituximab. OCILy-3, OCILy-10 and SuDHL-4 cells were treated as in panel A but analyzed for cell death using Annexin V and propidium iodine stainings.

whereas only $8 \%$ of the rituximab treated OCILy- 3 cells died in comparison to controls.

OCILy-3, OCILy-10 and SuDHL-4 represent DLBCLs, which have been previously specified as $\mathrm{ABC}$ and GC type cells (25). In order to ensure the molecular entities, we examined the protein expression of a panel of three molecular markers by Western blotting. We used a well described algorithm that exploits the immunohistochemical detection of CD10, Bcl-6 and MUM1/IRF4 protein expression and is used to predict the classification of DLBCL (26). As seen in Fig. 3, the SuDHL-4 cells expressed GC markers Bcl-6 and CD10, whereas the OCILy-3 cells were MUM1-positive and Bcl-6 and CD10-negative, representing ABC-like phenotype. In contrast to previous gene expression based classification, immunophenotyping identified OCILy-10 cells as GC subtype. As the GC-like SuDHL-4 and OCILy-10 cells were susceptible to the treatment but the ABC-like OCILY-3 


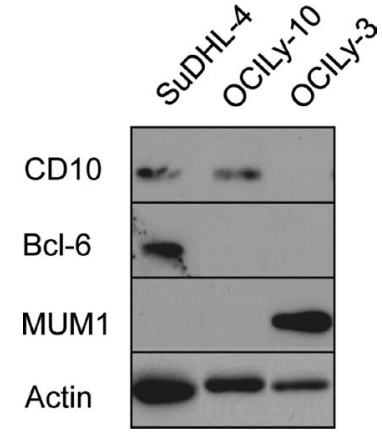

Figure 3. Expression of CD10, BCL-6 and MUM-1/IRF4 in DLBCL cell lines. Protein lysates were prepared and equal amounts of total proteins were subjected to SDS-PAGE followed by immunoblotting using antibodies against CD10, BCL-6 and MUM-1/IRF4 proteins. Actin was used as a loading control.

was not, this study suggests a possible link between direct cytotoxic response to rituximab and the cell of origin.

Gene expression associated with rituximab response. There is precedent for the use of microarrays to identify genes that may be important in therapeutic response of lymphomas. To explore rituximab-mediated molecular response mechanisms in DLBCL, we applied expression array technology. Gene expression patterns of the SuDHL-4, OCILy-10 and OCILy-3 cells were analyzed using Agilent oligonucleotide microarrays. The cells were exposed to rituximab for $3 \mathrm{~h}$, and the mRNA levels were compared to the untreated cells of the same DLBCL line. We chose to consider relevant only changes in gene expression that were of two-fold or over (fold change $\geq 2$ ) and found that rituximab induced expression of 515 and 620 genes in SuDHL-4 and OCILy-10 cells and suppressed 994 and 474 transcripts, respectively. To guard against cell line-specific responses, we searched for genes more than two-fold induced or suppressed in both rituximab responsive cell lines but remained relatively stable (fold change $\leq 1.2$ ) in the non-responsive cells. Accordingly, we identified 159 common genes that were up-regulated in rituximab responsive SuDHL-4 and OCILy-10 cells, and 93 genes that were suppressed. Of these 252 genes, 84 genes remained unchanged in OCILy-3 cells, and were considered as candidate genes (Fig. 4A). It is essential to recognize that in the resistant OCILy-3 cells, 132 genes were at least 2 -fold suppressed and 218 genes up-regulated in response to rituximab. This suggests that rituximab attaches to the CD20 receptor on the surface of OCILy-3 cells and starts a signaling cascade that eventually leads to changes in the gene expression in the nucleus.

Of the 84 candidate genes, 41 were up- and 43 down-regulated, implying that activation and suppression of transcription are equally affected by rituximab. Representative genes that increased or suppressed the most after rituximab treatment in two responsive cell lines are shown in Table I. Many of these genes are known to significantly affect apoptosis, lymphocyte signaling and cytokine response.

Validation of microarray data by quantitative PCR. To validate the results, we used qPCR on three genes segregating the rituximab responsive and non-responsive cells. The genes $D k k-1$,
A

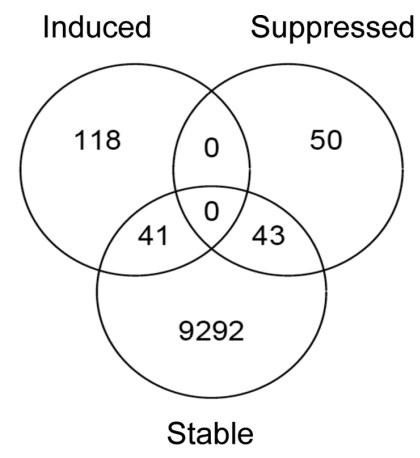

B
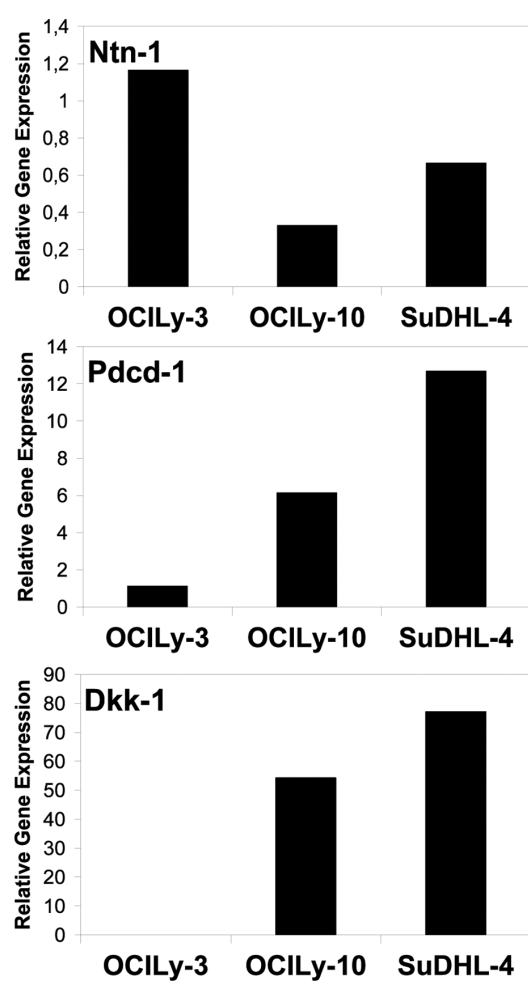

Figure 4. (A) Amount of genes overexpressed, suppressed or remaining stable in response to rituximab. (B) Expression of Ntn-1 Pdcd-1 and Dkk-1 in DLBCL cells in response to rituximab. mRNA isolated from control and rituximab-treated lymphoma cells at $3 \mathrm{~h}$ was analyzed by qPCR for the expression of Ntn-1 Pdcd-1 and Dkk-1 mRNAs. Data represent one of 3 repetitive experiments and is presented as fold change in comparison to expression level of the control cells.

$P d c d-1$ and Ntn-1 were selected from the group of the most differentially expressed genes with an interesting biological function. The qPCR results supported the microarray data showing Ntn-1 to be suppressed and Pdcd-1 and Dkk-1 induced in the rituximab stimulated responsive cells (Fig. 4B).

Gene ontologies. Although analysis of gene expressions can provide insights into important aspects of rituximab action, the overall mechanism is a complex phenomenon that needs to be investigated at the level of biological processes and pathways. The group of 84 candidate genes was analyzed for their ontologies based on three broad ontology categories: the particular part of the cell (cellular component); the activities of individual gene products (molecular function); and their integration with other genes to form a defined function (biological process). The major biological process 
Table I. Rituximab-responsive genes.

\begin{tabular}{|c|c|c|c|c|}
\hline Entrez & Name & $\begin{array}{l}\text { Fold } \\
\text { change }\end{array}$ & Gene description & Pathway \\
\hline 22943 & DKK1 & 61.99 & Dickkopf homolog 1 (Xenopus laevis) & Wnt \\
\hline 2792 & GNGT1 & 15.81 & $\begin{array}{l}\text { Guanine nucleotide binding protein ( } G \text { protein), } \\
\gamma \text { transducing activity polypeptide } 1\end{array}$ & Chemokine signaling pathway \\
\hline 5133 & PDCD1 & 6.25 & Programmed cell death 1 & T-cell receptor signaling \\
\hline 2043 & EPHA4 & 5.94 & EPH receptor A4 & Axon guidance \\
\hline 9047 & SH2D2A & 5.72 & $\mathrm{SH} 2$ domain protein $2 \mathrm{~A}$ & VEGF \\
\hline 7850 & IL1R2 & 3.81 & Interleukin 1 receptor II & MAPK, cytokine-cytokine receptor \\
\hline 330 & BIRC3 & 2.84 & Baculoviral IAP repeat-containing 3 & $\begin{array}{l}\text { Apoptosis, focal adhesion, small cell } \\
\text { lung cancer }\end{array}$ \\
\hline 81285 & OR51E2 & 2.72 & Olfactory receptor 51E2 & Olfactory transduction \\
\hline 1844 & DUSP2 & 2.37 & Dual specificity phosphatase 2 & MAPK \\
\hline 5788 & PTPRC & 2.33 & Protein tyrosine phosphatase $\mathrm{C}$ & $\begin{array}{l}\text { T-cell receptor signaling pathway, } \mathrm{Fc} \gamma \\
\text { R-mediated phagocytosis }\end{array}$ \\
\hline 2562 & GABRB3 & 2.18 & $\gamma$-aminobutyric acid (GABA) A receptor $\beta 3$ & Neuroactive ligand-receptor interaction \\
\hline 9423 & NTN1 & 0.09 & Netrin 1 & Axon guidance \\
\hline 4086 & SMAD1 & 0.19 & SMAD family member 1 & TGF- $\beta$ \\
\hline 7043 & TGFB3 & 0.21 & Transforming growth factor $\beta 3$ & $\begin{array}{l}\text { MAPK, cytokine-cytokine receptor } \\
\text { interaction, TGF- } \beta \text {, colorectal cancer, } \\
\text { renal cell carcinoma, pancreatic cancer, } \\
\text { CML }\end{array}$ \\
\hline
\end{tabular}

ontologies were related to signal transduction $(\mathrm{P}=0.016)$, regulation of apoptosis $(\mathrm{P}=0.028)$, system development $(\mathrm{P}=0.003)$ and cellular developmental processes $(\mathrm{P}=0.009)$. The molecular functions of the identified genes favored signal transducer activity $(\mathrm{P}=0.07)$ and were mainly associated with membranes $(\mathrm{P}=0.036)$ and extracellular matrix $(\mathrm{P}=0.06)$. Our results indicate that the candidate genes function in cellular processes that are known to drive cancer progression and drug resistance.

Signaling pathways involved in rituximab response. As our goal was to specify the molecular events that follow the binding of rituximab to CD20, we executed a pathway analysis that would reveal more about the rituximab-induced cell signaling in DLBCL. Enriched cell signaling pathways were organized according to a score that is based on the number of genes involved in a pathway in the KEGG pathway database and the estimated impact of these genes to the signaling pathway $(27,28)$. The most important pathways associated with the responsiveness to rituximab are shown in Table I. Overall, the data show that rituximab-response is associated with gene expression involved in classical pathways that control cell growth, differentiation and apoptosis. Some genes, for example Ntn-1 and Epha4, mapped to an unusual axon guidance pathway most likely due to the fact that the KEGG axon guidance pathway contains the whole MAPK pathway and several other cascades important in development in general and tumorigenesis in particular. Of the biologically relevant pathways, rituximab appeared to impact most the genes involved in TGF- $\beta$ and MAPK signaling pathways followed by Wnt and chemokine signaling pathways and apoptosis.
Clinical importance of Dusp2, Epha4, Dkk-1 and Netrin-1 in $D L B C L$. To explore the possible clinical relevance of our findings, we analyzed the prognostic significance of several interesting genes that were highly up- or down-regulated in response to rituximab. In these analyses we used an available data set from the Lymphoma/Leukemia Molecular Profiling Project (14), containing gene expression profiles from 233 DLBCL patients that were treated with the combination of rituximab and chemotherapy.

At the median follow-up of 33 months (range, 2-123 months), 60 patients $(26 \%)$ had died. The predicted 3 -year overall survival for the entire group was $73 \%$. Interestingly, the 3-year OS for the patients with high Dusp2 expression was $82 \%$ compared to $67 \%$ of those with low levels $(\mathrm{P}=0.051$, Fig. 5A). The corresponding values for the Epha4 high and low groups were 77 and 62\%, respectively ( $P=0.037$, Fig. 5B). A trend towards better 3-year OS was also seen among the patients with high $D k k-1$ expression (84 vs. $65 \%, \mathrm{P}=0.082$, Fig. 5C). On the contrary, low Netrin-1 levels tended to act as a favourable marker (3-year OS 77 vs 69\%, p=0.084, Fig. 5D). The results suggest that the expression of these rituximab responsive genes in lymphoma tissue has clinical significance for rituximab and CHOP treated DLBCL patients.

\section{Discussion}

Microarray technology is a powerful tool for investigating cellular responses to drugs because it monitors thousands of genes simultaneously. In the present study we used microarray-based transcriptional profiling to identify differentially expressed genes common to rituximab responsive DLBCL cell lines, but remaining stable in the unresponsive cells. 

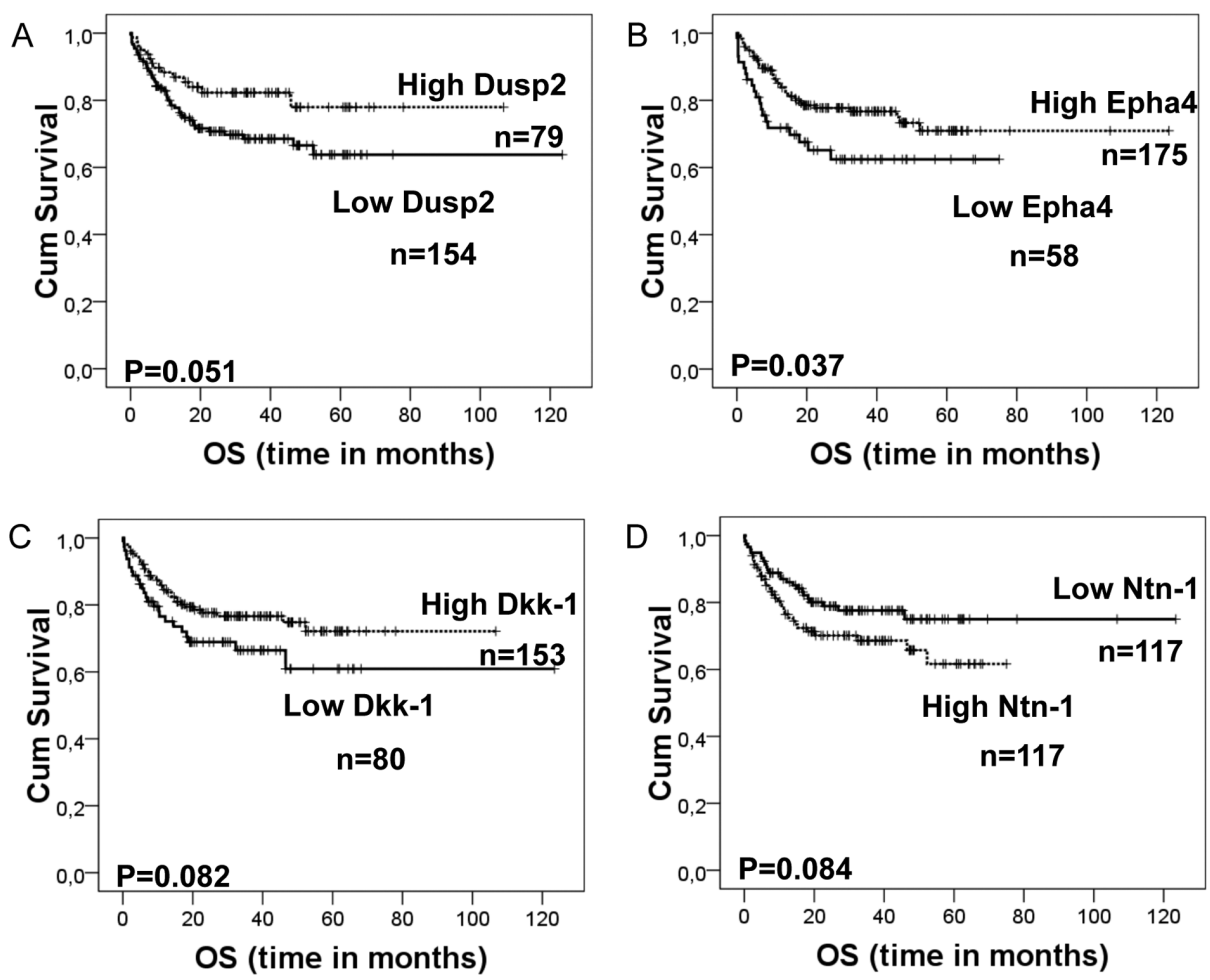

Figure 5. Survival rates according to mRNA expression. (A) OS of patients according to low ( $\mathrm{n} \leq 66 \%, \mathrm{n}=154)$ and high ( $\mathrm{n}>66 \%$, $\mathrm{n}=79)$ Dusp2 $\mathrm{mRNA}$ levels (B) OS of patients according to low $(\mathrm{n} \leq 25 \%, \mathrm{n}=58)$ and high $(\mathrm{n}>25 \%, \mathrm{n}=175)$ Epha4 mRNA levels. (C) OS of patients according to low ( $\leq 33 \%, \mathrm{n}=80)$ and high $(\mathrm{n}>33 \%, \mathrm{n}=153)$ Dkk-1 mRNA levels. OS of patients according to low (n $\leq$ median, $\mathrm{n}=171)$ and high $(\mathrm{n}>$ median, $\mathrm{n}=171)$ Ntn-1 mRNA levels.

Many genes were found to associate with signal transduction and regulation of apoptosis. All of this is consistent with our findings that rituximab treatment triggered direct cell death in the responsive cells. Important new insights into rituximab response include the convergence with the genes involved in TGF- $\beta$, MAPK and Wnt signaling. We found certain genes like Dkk-1, Pdcd-1, Netrin-1 and Smad-1 from these aforementioned pathways to be particularly biologically interesting, as recent studies have demonstrated their involvement in different malignancies.

Dickkopf-1 (Dkk-1) represents a gene, whose transcript increased the most after rituximab treatment in the responsive cell lines. Dkk-1 is a secreted protein that was discovered by its ability to block Wnt signaling during early Xenopus embryogenesis. Since then Dkk-1 has been shown to block the Wnt pathway in many cell types and vertebrate species (29). During embryonic development expression of $D k k-1$ has been shown to enhance apoptosis, whereas in cancer cells, overexpression of $D k k-1$ reduces colony formation and tumor growth in xenografts, suggesting a tumor-suppressor function $(30,31)$. Interestingly, Wnt pathway has been recently shown to be constitutive active in a subset of lymphomas, whereas inhibition of the pathway decreases lymphoma cell growth $(32,33)$.

Another interesting rituximab-inducible gene, programmed cell death 1 (Pdcd-1) (PD-1) encodes a cell surface protein that belongs to the superfamily of immunoglobulins. It is usually associated with T-cell activation but has also been reported to inhibit B cell proliferation and cytokine production (34). Recently $P d c d-1$ has been shown to play a role in lymphoid malignancies. High numbers of PD-1-positive tumor infiltrating T-cells was found to predict a better outcome in patients with follicular lymphoma (35). Furthermore, PD-1 has been shown to inhibit BCR mediated signaling in B cell lymphoma cell line and the expression of PD-1 in malignant $\mathrm{B}$ cells in vivo has also been described $(36,37)$.

Of particular interest in this data set is the suppression of Netrin-1 (Ntn-1). Netrin-1 is a well known ligand of a known tumor suppressor gene Deleted in colon cancer $(D c c)$. Dcc encodes a dependence receptor that has been shown to induce apoptosis in the absence of its ligand $(38,39)$. The overexpression of Netrin-1 has been reported to be of an advantage for tumor cells to survive in several cancers and similarly the down-regulation of netrin/Dcc signaling has been associated with tumor cell death in breast, lung, inflammatory bowel diseases-associated and colorectal cancer as well as neuroblastoma (40). Our studies demonstrate for the first time the association of Netrin-1 suppression to cell death in lymphoma DLBCL cells.

Smad-1 is a transcription factor that mediates gene expression in response to BMP and TGF- $\beta$ signaling. In many cell types, including B lymphocyte lineage, Smad-1 can serve as a mediator of growth arrest and apoptosis $(41,42)$. Controversially, TGF- $\beta$ has also been shown to contribute to growth and differentiation of B lymphocytes (43). Although Smad1 has been regarded to be activated mainly by BMPs, Munoz et al presented a growth regulatory role for Smad-1 and TGF- $\beta$ in follicular lymphoma cells (44). Our study implies that Smad-1 plays a role in the growth inhibition of DLBCL and raises a question of the functional meaning of such a considerable suppression of both TGFB3 and Smad-1 in response to rituximab. 
In recent years the knowledge on cell signaling has grown tremendously and old well-known factors have got new meanings in biological processes and tissues. In this light of events, especially intriguing is the Wnt-signaling pathway that has a profound role in developmental biology and now in increasing amounts can be associated to malignancy in cancer. New insights have also been taken with signaling events previously linked to axon guidance. We found two mediators Epha4 and Netrin-1 from this pathway among the most differentially expressed genes related to rituximab response in DLBCL cells ever strengthening the status of this pathway in cancer biology.

Cellular studies are the foundation for investigation, but the findings need to be carefully confirmed with patient samples. To evaluate the possible clinical relevance of our findings we analyzed the mRNA expression of Dusp2, Epha4, Dkk-1 and Netrin- 1 in a dataset of 233 rituximab and CHOP treated DLBCL patients (14). In our analyses the expression of Dusp2 and Epha4 in the lymphoma tissue correlated with the survival and based on these data also Dkk-1 and Netrin-1 may have a role in evaluating the outcome. The results strengthen the relevance of the findings from our cellular studies by suggesting that the expression of these genes in the lymphoma tissue is linked to the survival of DLBCL patients treated with rituximab and chemotherapy. These findings form an interesting basis for further studies in determining the usefulness of these markers.

Collectively, the results presented here show that rituximab response in DLBCL cells is associated with differential expression of several genes and pathways that are key regulators of proliferation and apoptosis. Future studies are needed to address whether for example up-regulation of $D k k-1$ acts as key signal to mediate the rituximab-induced apoptosis in DLBCL cells. Conversely, it remains to be determined whether suppression of Netrin-1 expression could impact the responsiveness of DLBCL patients to rituximab. Further studies are also expected to elucidate whether regulation of these genes may serve as new biomarkers of response to rituximab. If confirmed, targeting of these soluble proteins may lead to improvements in rituximab-containing treatment protocols.

\section{Acknowledgements}

We thank Drs Michael Wenger and Christian Klein for comments on the manuscript. The study was supported by grants from the Finnish Academy of Sciences, Finnish Cancer Societies, Sigrid Juselius Foundation, University of Helsinki, and Helsinki University Central Hospital. Rituximab (MabThera ${ }^{\circledR}$ ) was provided by Roche.

\section{References}

1. Tedder TF, Forsgren A, Boyd AW, Nadler LM and Schlossman SF: Antibodies reactive with the B1 molecule inhibit cell cycle progression but not activation of human B lymphocytes. Eur J Immunol 16: 881-887, 1986.

2. Tedder TF and Engel P: CD20: a regulator of cell-cycle progression of B lymphocytes. Immunol Today 15: 450-454, 1994.

3. Deans JP, Kalt L, Ledbetter JA, Schieven GL, Bolen JB and Johnson P: Association of $75 / 80-\mathrm{kDa}$ phosphoproteins and the tyrosine kinases Lyn, Fyn, and Lck with the B cell molecule CD20. J Biol Chem 270: 22632-22638, 1995.
4. Mathas S, Rickers A, Bommert K, Dorken B and Mapara MY: Anti-CD20- and B-cell receptor-mediated apoptosis: evidence for shared intracellular signaling pathways. Cancer Res 60: 7170-7176, 2000

5. Pedersen IM, Buhl AM, Klausen P, Geisler CH and Jurlander J: The chimeric anti-CD20 antibody rituximab induces apoptosis in B-cell chronic lymphocytic leukemia cells through a p38 mitogen activated protein-kinase-dependent mechanism. Blood 99: 1314-1319, 2002

6. Kheirallah S, Caron P, Gross E, et al: Rituximab inhibits B-cell receptor signaling. Blood 115: 985-994, 2010.

7. Bonavida B: Rituximab-induced inhibition of antiapoptotic cell survival pathways: implications in chemo/immunoresistance, rituximab unresponsiveness, prognostic and novel therapeutic interventions. Oncogene 26: 3629-3636, 2007.

8. Leseux L, Laurent G, Laurent C, Rigo M, Blanc A, Olive D and Bezombes C: PKC \{zeta\} mTOR pathway: a new target for rituximab therapy in follicular lymphoma. Blood 111: 285-291, 2008.

9. Coiffier B, Lepage E, Briere J, et al: CHOP chemotherapy plus rituximab compared with $\mathrm{CHOP}$ alone in elderly patients with diffuse large-B-cell lymphoma. N Engl J Med 346: 235-242, 2002.

10. Pfreundschuh M, Trümper L, Österborg A, et al: CHOP-like chemotherapy plus rituximab versus CHOP-like chemotherapy alone in young patients with good-prognosis diffuse large-B-cell lymphoma: a randomised controlled trial by the MabThera International Trial (MInT) Group. Lancet Oncol 7: 379-391, 2006.

11. Pfreundschuh M, Schubert J, Ziepert M, et al: Six versus eight cycles of bi-weekly CHOP-14 with or without rituximab in elderly patients with aggressive $\mathrm{CD} 20^{+} \mathrm{B}$-cell lymphomas: a randomised controlled trial (RICOVER-60). Lancet Oncol 9: 105-116, 2008.

12. Alizadeh AA, Eisen MB, Davis RE, et al: Distinct types of diffuse large B-cell lymphoma identified by gene expression profiling. Nature 403: 503-511, 2000.

13. Rosenwald A, Wright G, Leroy K, et al: Molecular diagnosis of primary mediastinal B cell lymphoma identifies a clinically favorable subgroup of diffuse large B cell lymphoma related to Hodgkin lymphoma. J Exp Med 198: 851-862, 2003.

14. Lenz G, Wright G, Dave SS, et al: Stromal gene signatures in large-B-cell lymphomas. N Engl J Med 359: 2313-2323, 2008.

15. Reff M, Carner K, Chambers K, et al: Depletion of B cells in vivo by a chimeric mouse human monoclonal antibody to CD20. Blood 83: 435-445, 1994.

16. Kennedy AD, Solga MD, Schuman TA, et al: An anti-C3b(i) $\mathrm{mAb}$ enhances complement activation, $\mathrm{C} 3 \mathrm{~b}(\mathrm{i})$ deposition, and killing of $\mathrm{CD}^{2} 0^{+}$cells by rituximab. Blood 101: 1071-1079, 2003.

17. Golay J, Zaffaroni L, Vaccari T, et al: Biologic response of $\mathrm{B}$ lymphoma cells to anti-CD20 monoclonal antibody rituximab in vitro: CD55 and CD59 regulate complement-mediated cell lysis. Blood 95: 3900-3908, 2000.

18. Smith MR: Rituximab (monoclonal anti-CD20 antibody): mechanisms of action and resistance. Oncogene 22: 7359-7368, 2003.

19. Shan D, Ledbetter JA and Press OW: Signaling events involved in anti-CD20-induced apoptosis of malignant human B cells. Cancer Immunol Immunother 48: 673-683, 2000.

20. Kajanne R, Miettinen P, Mehlem A, et al: EGF-R regulates MMP function in fibroblasts through MAPK and AP-1 pathways. J Cell Physiol 212: 489-497, 2007.

21. Hubbard TJP, Aken BL, Ayling S, et al: Ensembl 2009. Nucleic Acids Res 37: D690-D697, 2009.

22. Benjamini Y and Hochberg Y: Controlling the false discovery rate: a practical and powerful approach to multiple testing. J R Stat Soc Series B Methodol 57: 289-300, 1995.

23. Cittera E, Onofri C, D'Apolito M, et al: Rituximab induces different but overlapping sets of genes in human B-lymphoma cell lines. Cancer Immunol Immunother 54: 273-286, 2005.

24. Sarosiek KA, Malumbres R, Nechushtan H, Gentles AJ, Avisar E and Lossos IS: Novel IL-21 signaling pathway up-regulates c-Myc and induces apoptosis of diffuse large B-cell lymphomas. Blood 115: 570-580, 2010.

25. Davis RE, Brown KD, Siebenlist U and Staudt LM: Constitutive nuclear factor kappaB activity is required for survival of activated B cell-like diffuse large B cell lymphoma cells. J Exp Med 194: 1861-1874, 2001.

26. Hans CP, Weisenburger DD, Greiner TC, et al: Confirmation of the molecular classification of diffuse large B-cell lymphoma by immunohistochemistry using a tissue microarray. Blood 103: 275-282, 2004 
27. Kanehisa M, Goto S, Furumichi M, Tanabe M and Hirakawa M KEGG for representation and analysis of molecular networks involving diseases and drugs. Nucleic Acids Res 38: D355-D360, 2010.

28. Tarca AL, Draghici S, Khatri P, et al: A novel signaling pathway impact Analysis (SPIA). Bioinformatics 25: 75-82, 2008.

29. Niehrs C: Function and biological roles of the Dickkopf family of Wnt modulators. Oncogene 25: 7469-7481, 2006.

30. Grotewold L and Ruther U: Bmp, Fgf and Wnt signalling in programmed cell death and chondrogenesis during vertebrate limb development: the role of Dickkopf-1. Int J Dev Biol 46: 943-947, 2002.

31. Mikheev AM, Mikheeva SA, Maxwell JP, Rivo JV, Rostomily R, Swisshelm K and Zarbl H: Dickkopf-1 mediated tumor suppression in human breast carcinoma cells. Breast Cancer Res Treat 112: 263-273, 2008

32. Gelebart P, Anand M, Armanious H, Peters AC, Dien-Bard J, Amin HM and Lai R: Constitutive activation of the Wnt canonical pathway in mantle cell lymphoma. Blood 112: 5171-5179, 2008.

33. Kawahara T, Kawaguchi-Ihara N, Okuhashi Y, Itoh M, Nara N and Tohda S: Cyclopamine and quercetin suppress the growth of leukemia and lymphoma cells. Anticancer Res 29: 4629-4632, 2009.

34. Nishimura $\mathrm{H}$, Minato $\mathrm{N}$, Nakano $\mathrm{T}$ and Honjo $\mathrm{T}$ : Immunological studies on PD-1 deficient mice: implication of PD-1 as a negative regulator for B cell responses. Int Immunol 10: 1563-1572, 1998.

35. Carreras J, Lopez-Guillermo A, Roncador G, et al: High numbers of tumor-infiltrating programmed cell death 1-positive regulatory lymphocytes are associated with improved overall survival in follicular lymphoma. J Clin Oncol 27: 1470-1476, 2009.

36. Okazaki T, Maeda A, Nishimura H, Kurosaki T and Honjo T: PD-1 immunoreceptor inhibits B cell receptor-mediated signaling by recruiting src homology 2 -domain-containing tyrosine phosphatase 2 to phosphotyrosine. Proc Natl Acad Sci USA 98: 13866-13871, 2001.
37. Xerri L, Chetaille B, Seriari N, Attias C, Guillaume Y, Arnoulet $\mathrm{C}$ and Olive D: Programmed death 1 is a marker of angioimmunoblastic T-cell lymphoma and B-cell small lymphocytic lymphoma/chronic lymphocytic leukemia. Hum Pathol 39: 1050-1058, 2008

38. Mehlen P, Rabizadeh S, Snipas SJ, Assa-Munt N, Salvesen GS and Bredesen DE: The DCC gene product induces apoptosis by a mechanism requiring receptor proteolysis. Nature 395: 801-804, 1998.

39. Fearon ER, Cho KR, Nigro JM, et al: Identification of a chromosome 18q gene that is altered in colorectal cancers. Science 247: 49-56, 1990.

40. Mehlen P and Guenebeaud C: Netrin-1 and its dependence receptors as original targets for cancer therapy. Curr Opin Oncol 22: 46-54, 2010.

41. Ro TB, Holt RU, Brenne AT, et al: Bone morphogenetic protein-5, -6 and -7 inhibit growth and induce apoptosis in human myeloma cells. Oncogene 23: 3024-3032, 2004.

42. Kersten C, Sivertsen EA, Hystad ME, Forfang L, Smeland EB and Myklebust JH: BMP-6 inhibits growth of mature human B cells; induction of Smad phosphorylation and upregulation of Id1. BMC Immunol 6: 9, 2005.

43. Lebman DA and Edmiston JS: The role of TGF- $\beta$ in growth, differentiation, and maturation of B lymphocytes. Microb Infect 1: 1297-1304, 1999.

44. Munoz O, Fend F, de Beaumont R, Husson H, Astier A and Freedman AS: TGFbeta-mediated activation of Smad1 in B-cell non-Hodgkin's lymphoma and effect on cell proliferation. Leukemia 18: 2015-2025, 2004. 